\title{
L2 Acquisition of High Vowel Deletion in Québec French
}

\author{
Guilherme D. Garcia, Heather Goad, and Natália Brambatti Guzzo
}

\section{Introduction}

Research on second language (L2) acquisition has shown that learners' interlanguage grammars can accommodate variable phonological processes (see e.g., Beebe 1980, Bayley 1996, Romaine 2003). However, the acquisition of a variable process can be challenging if the factors that condition it are subtle. In this paper, we focus on such a case, High Vowel Deletion (HVD) in Québec French. HVD is conditioned by prosodic factors that are not reliably signaled in output strings.

In previous work (Garcia, Goad and Guzzo to appear), we observed that HVD in Québec French optimally applies in even-numbered syllables from the right word edge. We argued that this finding motivates iterative iambic footing in the language. In other words, native speakers judge as more natural words in which HVD applies in the dependent position within an iambic foot. This analysis is consistent with the cross-linguistic observation that deletion targets weak positions (e.g., Harris 1997). However, Québec French (like other varieties of French) does not exhibit the typical signatures of word-level stress and footing: the only obligatory position for prominence in the language is the right edge of a higher prosodic domain, namely, the phonological phrase (Dell 1984, Jun and Fougeron 2000 on European French; Thibault and Ouellet 1996 on Québec French). Thus, even though HVD is conditioned by word-internal structure, such structure is not signaled through the cues that normally mark prominence in surface strings.

French contrasts with languages that have lexical stress such as English: stress is computed in the phonological word and is realized (through cues to prominence) on the head syllable within the immediately lower prosodic constituent, the foot. Figure 1 shows the hierarchy of prosodic domains from the syllable $(\sigma)$ up to the phonological phrase (PPh) (based on Selkirk 1984, 1996; Nespor and Vogel 1986). The two domains located between the syllable and the

\footnotetext{
* Contact: Department of Linguistics, McGill University, Montréal, Québec, Canada; guilherme.garcia@mail.mcgill.ca, heather.goad@mcgill.ca, nataliaguzzo@me.com.Authors' names are in alphabetical order. We would like to thank Amélie Bernard, Jeff Lamontagne, Yvan Rose, Morgan Sonderegger and Francisco Torreira for their input on various aspects of this work. This research was supported by grants from SSHRC and FRQSC.
} 
$\mathrm{PPh}$, namely, the foot $(\mathrm{Ft})$ and the phonological word (PWd), cannot be identified in (Québec) French on the basis of prominence alone.

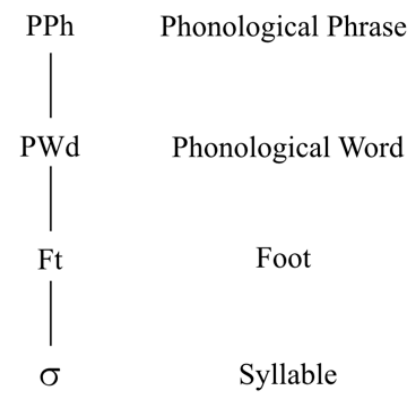

\section{Figure 1: The prosodic hierarchy (partial)}

The objective of this paper is to examine the L2 acquisition of HVD in Québec French by English-speaking learners. Specifically, we investigate whether these learners have acquired the prosodic conditioning of HVD, despite the lack of surface evidence for the prosodic structure that underlies the application of this process.

\section{Prosodic structure in English and French}

As mentioned above, English and (Québec) French differ regarding the domain in which prominence is manifested. In section 2.1 , we discuss these differences more concretely. We then turn, in section 2.2, to the prosodic system motivated by HVD in Québec French. We will see that although the English system of prominence provides learners with the necessary prosodic domain in which HVD optimally applies, namely the foot, most other aspects of the prosodic system of French motivated by HVD cannot be transferred from English. Thus, as will be detailed in section 2.3, English learners are challenged by two aspects of the triggering conditions for HVD, aside from its variability: (i) as mentioned above, the structure that conditions optimal application of HVD is not signaled through the cues that normally mark prominence in surface strings; (ii) many aspects of the prosodic structure required to capture HVD are different from those required for the assignment of prominence in English.

\subsection{Prominence in English and French}

In English, stress is realized in the foot and computed in the phonological word (Liberman and Prince 1977; Hayes 1995). English feet are trochaic and weight-sensitive, and in words where more than one foot is built, the rightmost foot is assigned primary stress. Final syllables in nouns are extrametrical: they 
are not factored into the computation of stress. These properties of English stress are illustrated in the example in (1).

(1) $\left[(\text { ærv })_{\mathrm{Ft}}(\text { ' } \mathrm{ka}:)_{\mathrm{Ft}} \mathrm{do \mho}\right]_{\mathrm{PWd}}$ 'avocado'

In French, on the other hand, the only obligatory position for prominence is the right edge of the phonological phrase, as shown in (2). This holds of both European French (Dell 1984; Jun and Fougeron 2000) and Québec French (Thibault and Ouellet 1996).

(2) [lə movez avo'ka $]_{P P h}$ le mauvais avocat 'the bad avocado'

The observation that phrase-internal PWds (such as mauvais in (2)) are not obligatorily prominent has motivated the analysis of French as a foot-less language (e.g., Jun and Fougeron 2000), in contrast to English and most other languages. ${ }^{1}$

\subsection{HVD as evidence for footing in Québec French}

Although the evidence from patterns of prominence alone does not support the postulation of a foot for French, another way to probe for the existence of this constituent is to look for segmental processes that seem to be sensitive to rhythm. HVD is one such process: as we will see shortly, it never applies wordfinally and it optimally targets high vowels in alternating non-final syllables from the right word edge. In earlier literature, however, the role of rhythmic structure in regulating HVD is disputed: whereas Verluyten (1982) suggests that HVD preferably targets even-numbered vowels from the right edge of the word, Cedergren (1986) argues that high vowels in any word-internal position can be deleted. Thus, both authors agree that HVD readily applies in words of the shape in (3a) but they disagree on whether it applies in words of the shape in (3b).

a. [kõbØne]

combiner

'to combine'

b. [organØzatœr]

organisateur

'organizer'

\footnotetext{
${ }^{1}$ The existence of foot structure in French is disputed (e.g., Scullen 1997). For a summary of evidence for and against the foot, see Goad and Prévost (2011).
} 
The disagreement between Verluyten (1982) and Cedergren (1986) seems to be rooted in the observation that HVD applies variably. When the conditions on variation are experimentally probed, however, it becomes clear that both authors are "right": HVD can apply in both types of words in (3) but it is preferred in words of the shape in (3a) (Garcia, Goad and Guzzo to appear). In the spirit of Verluyten, Garcia et al. use these findings to motivate right-to-left iterative iambic footing in Québec French. Deletion is preferred in foot dependent positions, as shown in (4), consistent with cross-linguistic patterns of reduction. In the examples in (4), foot heads are in bold. The head syllable in the head foot (head of the word) is underlined; as expected, when this vowel is high, it can never delete (e.g., *[armonØ] harmonie 'harmony').

\section{$[\mathrm{k} \tilde{s}(\mathrm{~b} \emptyset . \underline{n e})]>[\operatorname{or}($ ga.nØ $)(\mathrm{za} . \underline{\operatorname{tor}})]$}

\subsection{Challenges for English-speaking learners of HVD in Québec French}

English-speaking learners of Québec French face many challenges when acquiring HVD and the prosodic constraints that govern this process. As mentioned earlier, learners need to determine that although Québec French has no lexical stress (word level prominence), it nonetheless has feet. Further, Québec French builds feet iteratively from right-to-left, which regulates the application of HVD. However, HVD is variable: it does not always target high vowels in dependent position; and it can target high vowels in head position.

Finally, even if English-speaking learners notice that there is something rhythmic about HVD, they cannot rely on their L1 grammar of footing to correctly predict the location of deletion. Although both languages build feet iteratively from the right word edge, English builds bimoraic (weight-sensitive) trochees while French builds bisyllabic iambs. Stemming in part from this, final syllables in English are often weak, in all words where the final foot is bisyllabic and in nouns with final extrametricality, whereas final syllables in all French words are strong and thereby protected from deletion.

In view of the challenges that HVD presents, we hypothesize the following for English-speaking learners of Québec French: (a) because footing is not reliably signaled through prominence in French, (b) because HVD is a variable process, and (c) because footing operates differently in the two languages, learners will not understand the conditions under which HVD applies and thus their preferences will not mirror the preferences that hold of native speakers.

\section{Methods}

To test our hypothesis, we undertook an experiment where native speakers and learners were required to judge the well-formedness of Québec French words with and without HVD. 


\subsection{Participants}

Ten English-speaking learners of Québec French and ten native speaker controls participated in the experiment. The learners were originally from various locations in North America. All started learning Québec French in Montréal but use mostly English in their work or study environment. The learners completed a questionnaire which probed for their language background. This, combined with self-assessment of their French abilities in a variety of areas, led us to conclude that the proficiency of all of the learners was intermediate. The native speaker controls were all from the Montréal area, and had varying levels of proficiency in English.

\subsection{Stimuli and procedure}

The target stimuli consisted of 3- to 6-syllable words $(n=275)$, with deletion or non-deletion of [i] in non-final position. ${ }^{2}$ The high vowels were placed in open syllables following singleton onsets. No target words contained schwa. Fillers $(n=144)$ contained no high vowels. They exhibited presence or absence of deletion of mid or low vowels. The stimuli were recorded by a female native speaker of Québec French with training in Linguistics, with deletion being produced naturally. The stimuli were later checked in Praat (Boersma and Weenink 2016) for presence or absence of [i] in the target syllable.

The experiment was built in Praat. The stimuli were pseudorandomized and presented to participants both orthographically on a computer screen and auditorily through headphones. Orthographic presentation was necessary to ensure that the participants knew exactly what word they were listening to. ${ }^{3}$

Each auditory stimulus was preceded by a beep and was played only once. After hearing each stimulus, participants were instructed to judge whether it was pronounced in a natural way or not. Participants made their judgements using a 5 -point scale where 1 corresponded to completely unnatural and 5 to completely natural. Participants were instructed to use the computer keyboard to make their judgments. Each participant was run separately in a sound-attenuated booth located in the Department of Linguistics at McGill University. Each session lasted about 40 minutes, including two 5-minute breaks.

\footnotetext{
${ }^{2}$ We focused only on the vowel [i], given that it is reported to be the high vowel that is most frequently deleted in Québec French (Walker 1984). In addition, since deletion is a variable process, it is not our intention to discuss whether it is conditioned by vowel quality, but to investigate the rhythmic constraints that govern it.

${ }^{3}$ We did not include words which, after the application of deletion, could be confused with words with non-deletion (such as pilasse [pilas] 'to pound.PASTSUBJ', which could be confused with place [plas] 'place' in the case of [i] deletion).
} 


\subsection{Variables and predictions}

The stimuli were constructed so that HVD could apply in either foot-head or foot-dependent position. Recall that even-numbered syllables from the right word edge are in foot-dependent position, while odd-numbered syllables are in foot-head position (see examples in Table 1).

We also controlled for the shape of the consonant cluster resulting from HVD. The resulting cluster either mirrored a well-formed or an ill-formed branching onset (see examples in Table 1).

Finally, we divided the speakers into two groups: native speakers and learners.

Table 1: Variables included in the analysis

\begin{tabular}{|c|c|c|}
\hline \multicolumn{3}{|c|}{ Position of deletion in foot: } \\
\hline $\begin{array}{l}\text { Foot-dependent position } \\
\text { (syll. } 2 \text { or } 4) \\
\text { Foot-head position } \\
(\text { syll. } 3 \text { or } 5)\end{array}$ & 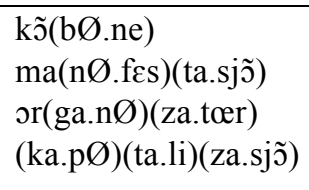 & $\begin{array}{l}\text { 'to combine' } \\
\text { 'demonstration' } \\
\text { 'organizer' } \\
\text { 'capitalization' }\end{array}$ \\
\hline \multicolumn{3}{|c|}{ Resulting consonant cluster: } \\
\hline Well-formed & $\begin{array}{l}\text { [pr] supØre } \\
\text { [bl] abØlite }\end{array}$ & $\begin{array}{l}\text { 'to sigh' } \\
\text { 'ability' }\end{array}$ \\
\hline Ill-formed & $\begin{array}{l}*[\mathrm{bn}] \mathrm{k} \tilde{\mathrm{z}} \mathrm{b} \text { ne } \\
*[\mathrm{mt}] \text { imØtatœr }\end{array}$ & $\begin{array}{l}\text { 'to combine' } \\
\text { 'impersonator' }\end{array}$ \\
\hline \multicolumn{3}{|l|}{ Group: } \\
\hline $\begin{array}{l}\text { Native speakers } \\
\text { Learners }\end{array}$ & & \\
\hline
\end{tabular}

\section{Predictions}

In section 2.3, we hypothesized that learners will not understand the conditions under which HVD applies and, thus, that their preferences will not mirror the preferences that hold of native speakers. Given the variables in Table 1 that we controlled, our specific predictions are as follows:

(i) Deletion vs. non-deletion: Neither native speakers nor learners will reject HVD, given that the process is reportedly frequent in the language (e.g., Walker 1984).

(ii) Position of deletion in foot: Unlike native speakers, learners will not be sensitive to the rhythmic conditions under which HVD is preferred. 
(iii) Resulting consonant cluster: Both native speakers and learners will disprefer HVD resulting in clusters that mirror well-formed branching onsets.

Concerning (iii), even if learners do not understand the conditions under which HVD applies, we predict that they should pattern like native speakers in dispreferring HVD that results in clusters that mirror well-formed branching onsets. Items in which the consonantal string resulting from HVD corresponds to a well-formed branching onset have ambiguous representations: an item such as [supØre] (from supirer 'to sigh') can be recovered as either/su.pre/ or /su.pV.re/, while an item such as [kõbØne] (from combiner 'to combine') can only be recovered as /k̃̃.bV.ne/ (V stands for any deletable vowel in French). Provided that learners understand the phonotactics of branching onsets in Québec French, they should be sensitive to recoverability in the same way that native speakers are.

\section{Results}

\subsection{Data}

We begin by examining participants' overall preferences for deletion vs. non-deletion. In general, non-deletion is preferred over deletion by both native speakers and learners (L2ers), as shown in Table 2. However, the means of the ratings for deletion are both above 2.5 , indicating that even though deletion is dispreferred overall, it is accepted as natural. This suggests that prediction (i) is supported.

Table 2: Overall ratings $(1=$ completely unnatural; $5=$ completely natural $)$ for deletion and non-deletion

\begin{tabular}{lll}
\hline Group & Deletion & Non-deletion \\
\hline Native & $\bar{x}=3.28, s=1.50$ & $\bar{x}=4.48, s=0.94$ \\
\hline L2er & $\bar{x}=3.44, s=1.48$ & $\bar{x}=4.31, s=1.04$ \\
\hline
\end{tabular}

Figure 2 shows participants' responses based on the position of HVD within the iambic foot. Figure 2 includes all possible positions of HVD in a word: the left panel shows the results for even-numbered syllables from the right word edge (syllables 2 and 4), while the right panel shows the responses for oddnumbered syllables from the right word edge (syllables 3 and 5). Both native speakers and learners have strikingly similar judgements: HVD in footdependent position (even-numbered syllables from the right edge of the word) yields a higher concentration of natural responses. This suggests that prediction (ii) is not supported. 


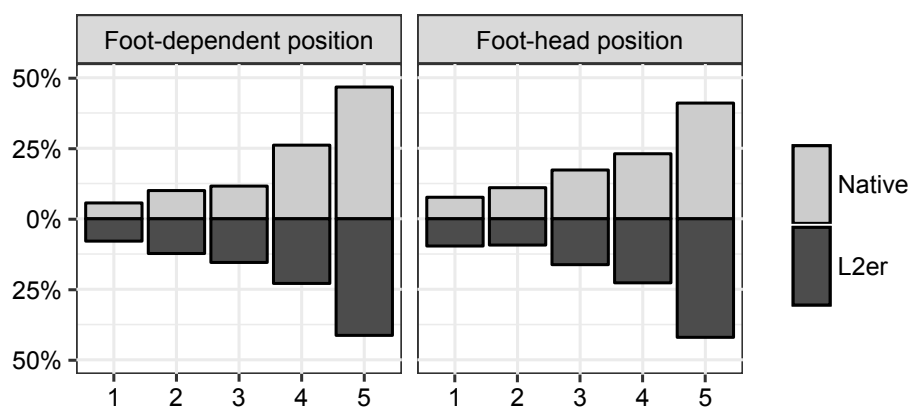

Figure 2: Responses based on position of deletion in foot ( 1 = completely unnatural; 5 = completely natural)

Figure 3 shows participants' responses based on resulting consonant cluster. Again, both native speakers and learners have remarkably similar judgements: HVD is preferred when the resulting cluster mirrors an ill-formed branching onset in Québec French. This shows that both groups of speakers are aware that forms in which deletion yields strings mirroring licit branching onsets can map to two possible inputs (with and without deletion). This suggests that prediction (iii) is supported.
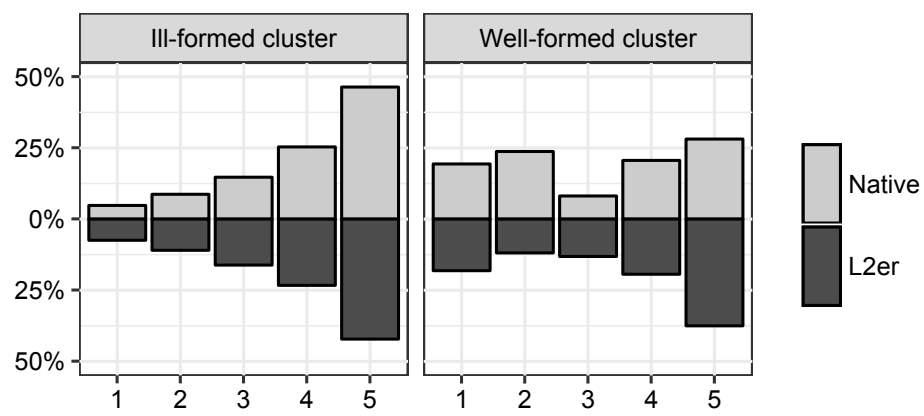

Figure 3: Responses based on resulting consonant cluster ( 1 = completely unnatural; 5 = completely natural)

\subsection{Statistical analysis}

We modeled participants' responses using a hierarchical ordinal regression with by-speaker and by-item random effects in $\mathrm{R}$ ( $\mathrm{R}$ Core Team 2016). The model included the variables listed in Table 1 as main effects, and controlled for participants' preferences with respect to deletion vs. non-deletion.

The model indicated no significant difference between native speakers' and second language learners' preferences $(\hat{\beta}=-0.11, p=0.85)$. For both groups of participants, non-deletion is preferred over deletion (e.g., organizatœr > organØzatœr 'organizer'; $\hat{\beta}=1.55, p=0.00001$; Table 2). 
Regarding position of deletion in foot, HVD is preferred in the weak position within an iambic foot (i.e., in even-numbered syllables from the right word edge). HVD is equally preferred in syllables 2 and 4, and equally dispreferred in positions 3 and 5 (e.g., kõbØne, manØfestasjõ 'to combine', 'demonstration' > organØzatœr, kapØtalizasj̃̃ 'organizer', 'capitalization'; $\hat{\beta}=$ $0.29, p=0.01$; Figure 2).

The results for the variable resulting consonant cluster show that HVD is dispreferred when the resulting consonantal string mirrors a phonotactically well-formed branching onset in Québec French (e.g., kõbØne 'to combine' > supØre 'to sigh'; $\hat{\beta}=-0.72, p=0.0002$; Figure 3 ).

In the next section, we turn to the discussion of these results in light of the predictions.

\section{Discussion and conclusion}

The statistical model could not find any significant difference between the two groups of speakers, as suggested by Table 2 and Figures 2 and 3. Both groups overall rate words with non-deletion better than words with deletion, and have similar judgements with respect to position of deletion in foot and resulting consonant cluster.

These results support predictions (i) and (iii) provided in section 4, which proposed, respectively, that speakers would not reject HVD, and that HVD resulting in strings mirroring well-formed branching onsets would be dispreferred. However, these results do not support prediction (ii), according to which only native speakers would be sensitive to the rhythmic constraints regulating the application of HVD. Instead, these results suggest that second language learners can acquire processes that are both variable and structurally conditioned, even when the structure that underlies them is not reliably signaled on the surface.

Native-like behavior on the part of the learners may seem particularly surprising as their proficiency level was only intermediate. In light of this, we must consider the possibility that the learners could have arrived at native-like performance through transfer. In order to formally capture HVD, the learners could transfer two aspects of the prosodic structure of English into the interlanguage grammar: the parsing of syllables into feet (i) is iterative and (ii) applies from right-to-left. However, as discussed in section 2, feet in English are trochaic and weight-sensitive, and final syllables in nouns are extrametrical. The preferences on the application of HVD suggest that feet in Québec French are iambic and that syllable weight and extrametricality do not influence their construction. Therefore, transfer is not a likely source for learners' behavior.

In conclusion, we have shown that interlanguage grammars can accommodate variable processes, even if the factors that condition them are not reliably detected in surface forms. 


\section{References}

Beebe, Leslie M. (1980). Sociolinguistic variation and style shifting in second language acquisition. Language Learning 30: 433-445.

Bayley, Robert. (1996). Competing constraints on variation in the speech of adult Chinese learners of English. In Bayley, Robert and Preston, Dennis (eds.) Second language acquisition and linguistic variation, pp. 97-120. Amsterdam: John Benjamins.

Boersma, Paul and Weenink, David. (2016). Praat: Doing phonetics by computer [Computer program]. Version 6.0.23.

Cedergren, Henrietta J. (1986). Metrical structure and vowel deletion in Montreal French. In Sankoff, David (ed.) Diversity and diachrony, pp. 293-300. Philadelphia: Benjamins.

Dell, François. (1984). L'accentuation dans les phrases en français. In Dell, François, Hirst, Daniel and Vergnaud, Jean-Roger (eds.) Forme sonore du langage, pp. 65122. Paris: Hermann.

Garcia, Guilherme D., Goad, Heather, and Guzzo, Natália Brambatti. (to appear). Footing is not always about stress: Formalizing high vowel deletion in Québec French. Proceedings of the Annual Meeting on Phonology 2016.

Goad, Heather and Prévost, Adèle-Elise. (2011). A test case for markedness: The acquisition of Québec French. Ms., McGill University.

Harris, John. (1997). Licensing inheritance: An integrated theory of neutralisation. Phonology 14: 315-370.

Hayes, Bruce. (1995). Metrical stress theory: Principles and case studies. Chicago: University of Chicago Press.

Jun, Sun-Ah and Fougeron, Cécile. (2000). A phonological model of French intonation. In Botinis, Antonis (ed.) Intonation: Analysis, modelling and technology, pp. 209242. Dordrecht: Kluwer.

Liberman, Mark and Prince, Alan. (1977). On stress and linguistic rhythm. Linguistic Inquiry 8: 249-336.

Nespor, Marina and Vogel, Irene. (1986). Prosodic phonology. Dordrecht: Foris.

R Core Team. (2016). R: A language and environment for statistical computing. R Foundation for Statistical Computing, Vienna, Austria. [Computer program].

Romaine, Suzanne. (2003). Variation. In Doughty, Catherine J. and Long, Michael H. (eds.) The handbook of second language acquisition, pp. 409-435. Oxford: Blackwell.

Scullen, Mary Ellen. (1997). French prosodic morphology: A unified account. Bloomington: IULC.

Selkirk, Elisabeth O. (1984). Phonology and syntax: The relation between sound and structure. Cambridge, MA: MIT Press.

Selkirk, Elisabeth O. (1996). The prosodic structure of function words. In Morgan, James L. and Demuth, Katherine (eds.) Signal to syntax: Bootstrapping from speech to grammar in early acquisition, pp. 187-213. Mahwah, NJ: Lawrence Erlbaum.

Thibault, Linda and Ouellet, Marise. (1996). Tonal distinctions between emphatic stress and pretonic lengthening in Quebec French. Proceedings of the International Spoken Language Conference 1996, Philadelphia, pp. 638-641.

Verluyten, Sylvain Paul Marcel. (1982). Recherches sur la prosodie et la métrique du français. PhD dissertation, Universiteit Antwerpen. 


\section{Proceedings of the 41st annual Boston University Conference on Language Development}

\section{edited by Maria LaMendola and Jennifer Scott}

Cascadilla Press Somerville, MA 2017

\section{Copyright information}

Proceedings of the 41st annual Boston University Conference on Language Development

(C) 2017 Cascadilla Press. All rights reserved

Copyright notices are located at the bottom of the first page of each paper.

Reprints for course packs can be authorized by Cascadilla Press.

ISSN 1080-692X

ISBN 978-1-57473-076-0 (2 volume set, paperback)

ISBN 978-1-57473-176-7 (2 volume set, library binding)

\section{Ordering information}

To order a copy of the proceedings or to place a standing order, contact:

Cascadilla Press, P.O. Box 440355, Somerville, MA 02144, USA

phone: 1-617-776-2370, sales@ cascadilla.com, www.cascadilla.com 